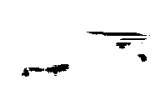

NASA TECHNICAL MEMORANDUM 102637

\title{
NASA AIRFRAME STRUCTURAL INTEGRITY PROGRAM
}

Charles E. Harris

\section{APRIL 1990}

(NASA-TM-10?O37) NASA AIPFRAME STRUCTURAL
INTEGRITY PROGRAM (NASA) 20 P O CSCL 2OK

$N 90-21422$

$$
\begin{array}{ll}
\text { Unclas } \\
\text { G3/39 } & 0277021
\end{array}
$$

\section{N/SA}

National Aeronautics and

Space Administration

Langley Research Center

Hampton, Virginia 23665-5225 


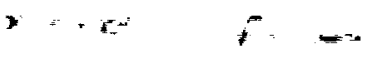

\author{
言
}

毫 


\title{
NASA Airframe Structural Integrity Program
}

\author{
Charles E. Harris, Head \\ Mechanics of Materials Branch \\ NASA Langley Research Center \\ Hampton, VA 23665
}

\section{SUMMARY}

NASA has initiated a research program with the long-term objective of supporting the aerospace industry in addressing issues related to the aging commercial transport fleet. The interdisciplinary program combines advanced fatigue crack growth prediction methodology with innovative nondestructive examination technology with the focus on multi-site damage (MSD) at riveted connections. A fracture mechanics evaluation of the concept of pressure proof testing the fuselage to screen for MSD has been completed. Also, a successful laboratory demonstration of the ability of the thermal flux method to detect disbonds at riveted lap splice joints has been conducted. All long-term program elements have been initiated and the plans for the methodology verification program are being coordinated with the airframe manufacturers.

\section{INTRODUCTION}

Basic research related to the fatigue and fracture of metals, computational fracture mechanics, structural analysis methods, and nondestructive examination (NDE) methods for material defect characterization have been ongoing at NASA Langley for many years. All of these disciplines have been brought to bear on the problems facing the aging commercial transport fleet. After participating in the two previous International Aging Aircraft Conferences and conducting a tour of the U. S. commercial transport manufacturers, NASA has identified several areas of concern where our ongoing research offers a potential solution. Therefore, in coordination with the FAA and the airframe manufacturers, NASA has developed a specialized research program that is an outgrowth of our base research program with the broad objectives of methodology specialization, verification, and technology transfer. The two key program elements are advanced fatigue crack growth prediction methodology applicable to complex built-up structure and innovative NDE technologies to detect fatigue cracks, corrosion, and disbonds in adhesively bonded joints. The focus of the program is multi-site damage (MSD) in unbonded lap splice joints. However, the research is generic in nature and the developed methodology is expected to be applicable to many other structural components that may be fracture critical. The purpose of this paper is to provide a brief overview of the relevant 
ongoing research at NASA Langley and to present the plans of the specialized Airframe Structural Integrity Program (ASIP).

\section{FATIGUE CRACK GROWTH PREDICTION METHODOLOGY}

The concept of crack closure to explain crack growth acceleration and retardation was pioneered at NASA Langley almost two decades ago. A plasticity-induced closure model [1] employing fracture mechanics principles was shown to be quite accurate in predicting the fatigue crack growth in aluminum alloys for a number of basic crack configurations for both constant amplitude and spectrum loadings. Furthermore, the closure model has been successfully used to explain the smallcrack phenomenon exhibited by many aluminum alloys. The crack closure concept is illustrated schematically in Figure 1. Residual plastic deformations produced by the crack-tip plastic zone causes residual compressive stresses in the wake of the advancing crack at the minimum load. These compressive stresses must be overcome before the crack is fully open on each loading cycle. Therefore, the full cyclic stress range is not effective in extending the crack. The crack growth rate data must be correlated with the effective stress-intensity factor range rather than the full range to yield meaningful predictions of total crack growth. Figure 2 illustrates the growth rate data for 2024-T3 which spans 8 orders of magnitude and couples the threshold behavior with large-scale stable tearing. The successful application of the closure model to predict small-crack growth rate data has resulted in a total life prediction methodology which treats initiation by predicting the growth of micron size cracks initiating at inclusion particles in the microstructure [2].

This type of methodology is necessary to predict the fatigue crack growth of small cracks initiating at a rivet hole before they grow to a detectable size. Furthermore, this methodology may be used to predict the necessary inspection intervals to monitor crack growth before critical sizes are reached and link-up of adjacent cracks occur. Therefore, one of the objectives of the ASIP is to specialize the closure methodology for riveted splice joint crack configurations.

A rigorous fracture mechanics treatment of cracks initiating at rivet holes and MSD will require the generation of stress intensity factor solutions to several basic crack configurations. NASA has developed several computational methods for computing stress intensity factor solutions to complex crack configurations. The boundary force method (BFM) [3], an indirect boundary element method, is well suited to two dimensional (2-D) problems such as the crack configuration illustrated in Figure 3a. For more complex problems, the finite element method with the force method or the 
virtual crack closure technique (VCCT) [4] have been successfully employed to obtain solutions to three dimensional (3-D) crack configurations. An example of this capability is illustrated in Figure $3 \mathrm{~b}$ for a surface crack emanating from a semicircular notch. These techniques will be used to generate the solutions to the two crack configurations shown in Figure 4 with the BFM being used to obtain 2-D solutions for MSD. Because MSD linkup is likely to be governed by net section yielding, an elastic-plastic analysis of the loaded rivet hole and a typical splice joint will also be required.

NASA has recently completed an evaluation of the concept of pressure proof testing the fuselage of aging airplanes as an augmentation to NDE. The evaluation was conducted from the fracture mechanics viewpoint by employing both the crack closure prediction methodology and flat panel test results. The results revealed that the remaining fatigue life of a structure with near critical cracks with the proof test is longer than without the proof test because of the effect of crack growth retardation. However, when repeated proof tests are conducted, the proof test interval required to insure failures during the proof test rather than in-flight will shorten the overall life of the structure. The required proof test interval to screen critical MSD in riveted splice joints would be every 275 cycles for a maximum proof test load of 1.33 times the normal cabin pressure. Complete details of this evaluation may be found in reference 5 .

\section{GLOBAL/LOCAL STRUCTURAL ANALYSIS METHODOLOGY}

The behavior of large cracks in fuselage structures such as mid-bay cracks or splice joint cracks after MSD linkup are strongly influenced by the stiffening effects of the circumferential frames and longitudinal stiffeners. It is not practical to model all of the structural details in a finite element analysis. Greater efficiency can be achieved by exploiting a global/local strategy where local details that produce stress gradients can be treated in a companion analysis to the global structural analysis. Figure 5 shows an example stress analysis of a circular cutout in a blade-stiffened panel where quite accurate results were obtained by the global/local analysis methodology [6]. To accurately predict the behavior of a growing crack in a stiffened shell structure, the global/local methodology must be extended to include an adaptive mesh concept so that the local refined mesh can change in a manner dictated by the growing crack. This concept is illustrated schematically in Figure 6 . The structural analysis methodology will have to account for geometric nonlinear behavior as well as large deformation behavior. This is necessary to predict the crack growth 
direction and crack opening of large cracks that may result in a rapid decompression rather than a catastrophic in-flight failure.

The fracture mechanics and global/local analysis methodology must be verified by an experimental test program. As shown in Figure 7, there are various levels of testing required to achieve a full verification of a structural analysis methodology. The goal of the ASIP program is to achieve verification through the curved panel and subscale barrel test article level. Tests of the coupons and flat panels shown schematically in Figure 8 required to verify the fracture mechanics solutions are already underway. However, we are investigating the possibility of using existing data from the damage tolerance tests previously conducted by the airframers as benchmarks for the structural analysis methodology in lieu of conducting new tests for the sole purpose of methodology verification.

\section{QUANTITATIVE NONDESTRUCTIVE EXAMINATION TECHNOLOGY}

A wide range of nondestructive measurements science research is ongoing at NASA Langley including defect characterization, stress and strain field mapping, and smart sensors for materials and structures. A number of NDE techniques under development at NASA are relevant to detecting fatigue cracks in aging aircraft. These techniques include thermography, ultrasonics, magnetics, and acoustic emission.

Perhaps the most promising technique in the near-term is an advanced thermal method which is based on heat flux rather than absolute temperature [7]. The thermal flux method has been demonstrated to be successful in detecting disbonds in lap splice joints as illustrated in Figure 9. This technique shows such great promise that NASA and the FAA have developed a technology transfer program and are tentatively planning a full scale field demonstration on an airplane at an inspection depot within the next year.

It is well known that the physical measurements from NDE techniques must be coupled with computational models such as those obtained from elasticity and fracture mechanics to provide useful quantitative defect characterization information. One of the goals of the ASIP program is to couple the disciplines of physics and mechanics to obtain a more thorough understanding of the crack growth process, more reliable experimental maps of the stress gradient fields produced by a crack, and more quantitatively useful NDE techniques for field inspection applications. The coupon and panel tests planned to verify the fracture mechanics solu- 
tions will rely on NDE measurements as well as provide a cross-reference on the utility of the NDE techniques. For example, the high resolution thermal method shown schematically in Figure 10 will be used to provide maps of the local stress gradient fields produced by a crack. This technique relies on a mathematical algorithm derived from thermoelasticity that relates the stress field to the temperature gradients measured by the infrared radiation emitted by the elastic body undergoing cyclic deformation. This information will provide a useful benchmark to the stress fields predicted by the fracture mechanics analyses. Also, a special facility shown schematically in Figure 11 has an x-ray cat scanner system mounted to a servohydraulic loading frame that is anticipated to provide 3-D images of microcracks in the 10-50 micron size. The 3-D image is constructed by processing $x$-ray exposures taken from various locations around the specimen. This technique will allow for the determination of both the orientation and crack growth increments of small cracks during testing rather than inferring this information from an examination of the fracture morphology after the specimen fails.

Finally, the long-range goal of the ASIP program is to develop user friendly, economical, and quantitatively reliable inspection techniques for field applications. In addition to the thermal flux method previously discussed, an ultrasonic phased array technique [8] currently under development shows promise as a candidate for field applications. The technique is similar to phased array RADAR and provides high resolution detection, image aberration correction, and quantitative characterization through signal processing. As illustrated in Figure 12, this technique has the potential to detect fatigue cracks and corrosion by scanning a relatively large fieldof-vision during the inspection.

\section{SUMMARY}

NASA has initiated a research program with the long-term objective of supporting the aerospace industry in addressing issues related to the aging commercial transport fleet. The interdisciplinary program combines advanced fatigue crack growth prediction methodology with innovative nondestructive examination (NDE) technology with the focus on multi-site damage (MSD) at riveted connections. The fatigue crack growth prediction methodology is centered around the plasticityinduced closure model developed at NASA which will be specialized for MSD and implemented into a global-local analysis scheme for analyzing a complex built-up structure such as a stiffened fuselage. The NDE technology will focus on advanced thermal, magnetics, and ultrasonics methods. Interdisciplinary laboratory research will focus on acquiring a more fundamental understanding of the physics of fatigue 
crack growth and will employ thermal methods for stress gradient field mapping and 3-D $x$-ray radiography for crack imaging. A methodology verification program will be coordinated with the airframe manufacturers to enhance our ability to achieve meaningful technology transfer.

All program elements have been initiated. A fracture mechanics evaluation of the concept of pressure proof testing the fuselage of aging airplanes to screen for MSD has been completed. The results of this evaluation indicate that the required proof test interval would have to be about 275 cycles to be considered as an augmentation to NDE. Current activities are focused on generating meaningful fracture mechanics solutions to 3-D crack configurations at single rivet holes and 2-D MSD configurations. The thermal flux method has been demonstrated to be capable of detecting a lap splice joint disbond in the laboratory. The near-term NDE plans are to conduct a field test demonstration of the thermal method at an inspection depot on an actual airplane.

\section{REFERENCES}

1. Newman, J. C., Jr., "A Crack Closure Model for Predicting Fatigue Crack Growth Under Aircraft Spectrum Loading," Methods and Models for Predicting Fatigue Crack Growth Under Random Loading, ASTM STP 748, American Society for Testing and Material, 1981, pp. 53-84.

2. Phillips, E. P. and Newman, J. C., Jr., "Impact of Small-crack Effects on DesignLife Calculations," Experimental Mechanics, Vol 29, No 2, June 1989, pp. 221 225.

3. Tan, P. W., Raju, I. S. and Newman, J. C., Jr., "Boundary Force Method for Analyzing Two-Dimensional Cracked Bodies," NASA TM-87725, May 1986.

4. Shivakumar, K. N., Tan, P. W. and Newman, J. C., Jr., "A Virtual Crack-Closure Technique for Calculating stress Intensity Factors for Cracked Three Dimensional Bodies," International Journal of Fracture, Vol. 36, 1988, pp. R43-R50.

5. Dawicke, D. S.; Poe, C. C., Jr.; Newman, J. C., Jr.; and Harris, C. E.; "An Evaluation of the Pressure Proof Test Concept for Thin Sheet 2024-T3," NASA TM-101675, 1990.

6. Ransom, J. B. and Knight, N. F., Jr., "Global/Local Stress analysis of Composite Panels," NASA TM-101622, 1989.

7. Winfree, W. P.; Welch, C. S.; James, P. H .; and Ciamer, E.; "Thermographic Detection of Delaminations in Laminated Structures," Review of Progress in Quantitative Nondestructive Evaluation, Edited by D. O. Thompson and D. E. Chimenti, Vol. 8, pp. 1657-1662, 1989.

8. Madaras, Eric I.; "Ultrasonic Phased Array Test Bed System (UPATS) with LaRC," Solicitation No. 1-33-1250-0258. 


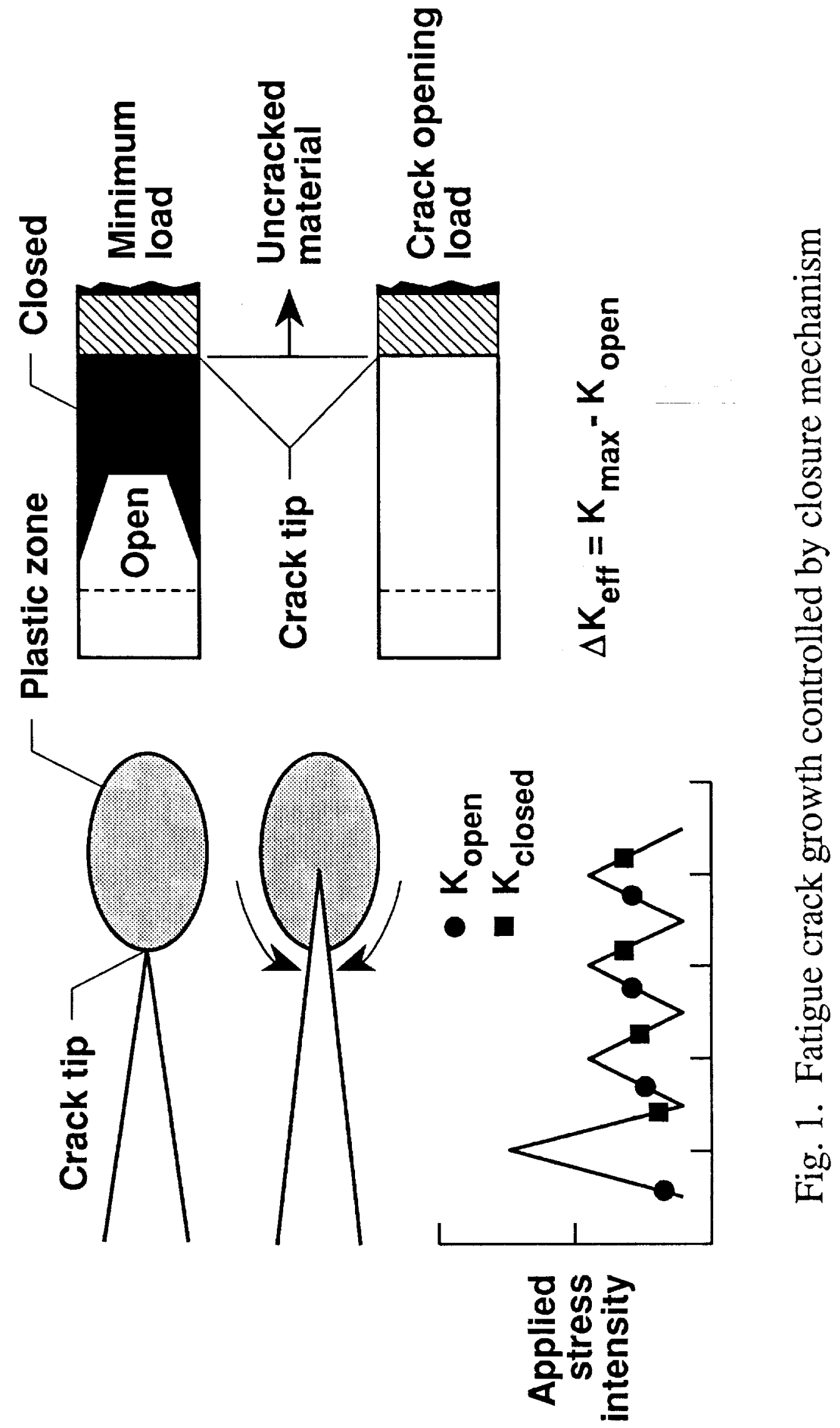




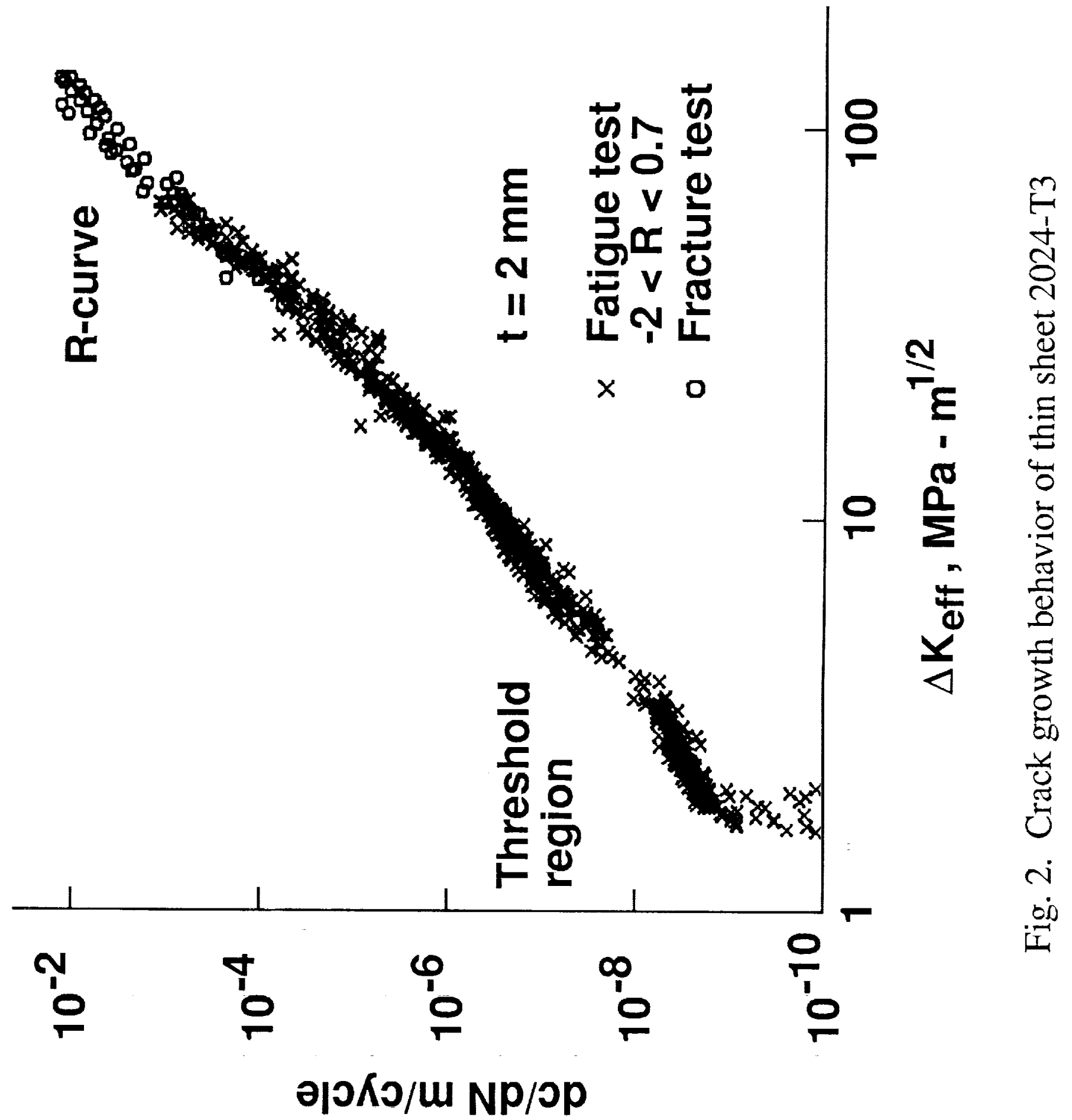




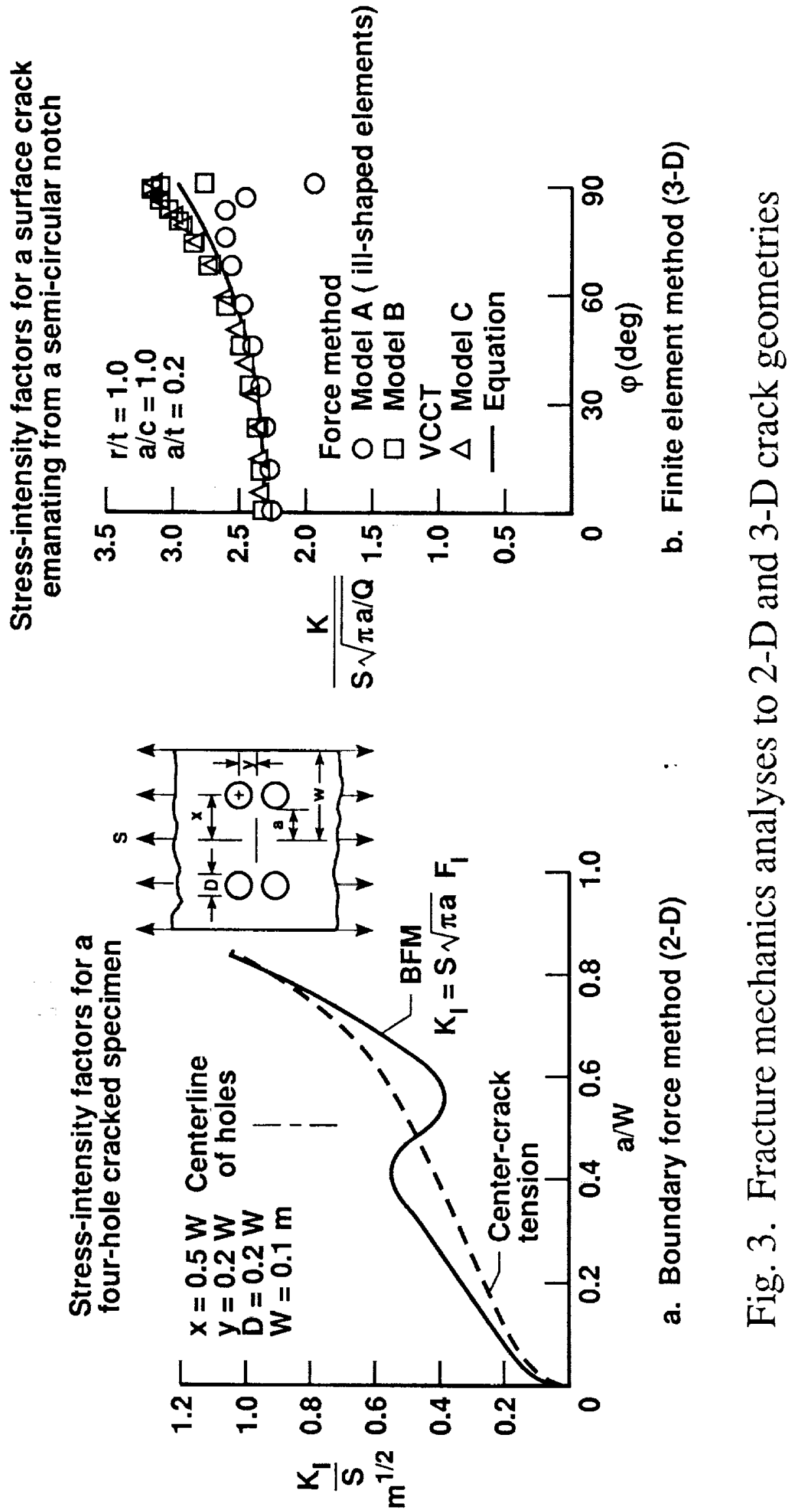




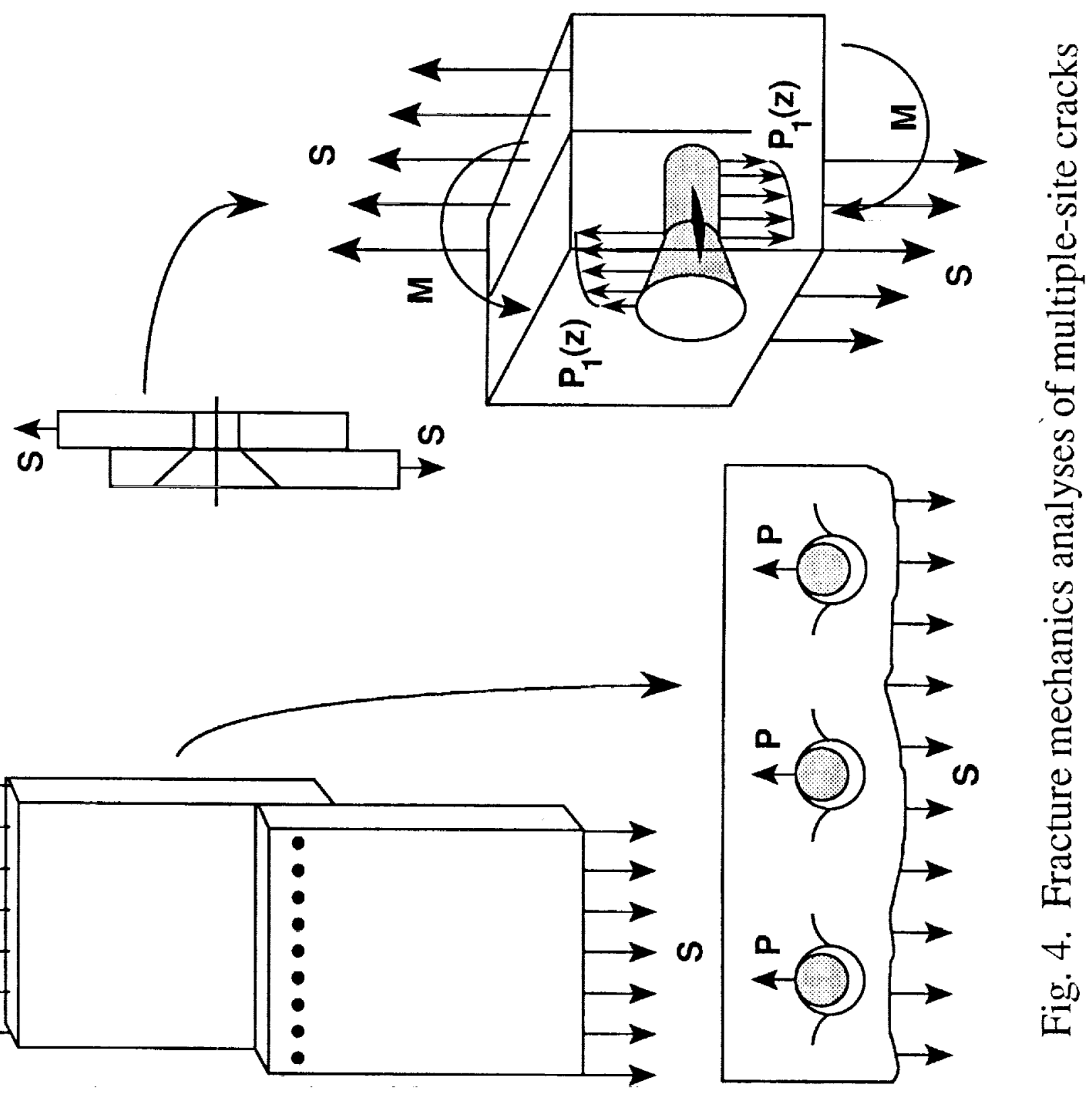




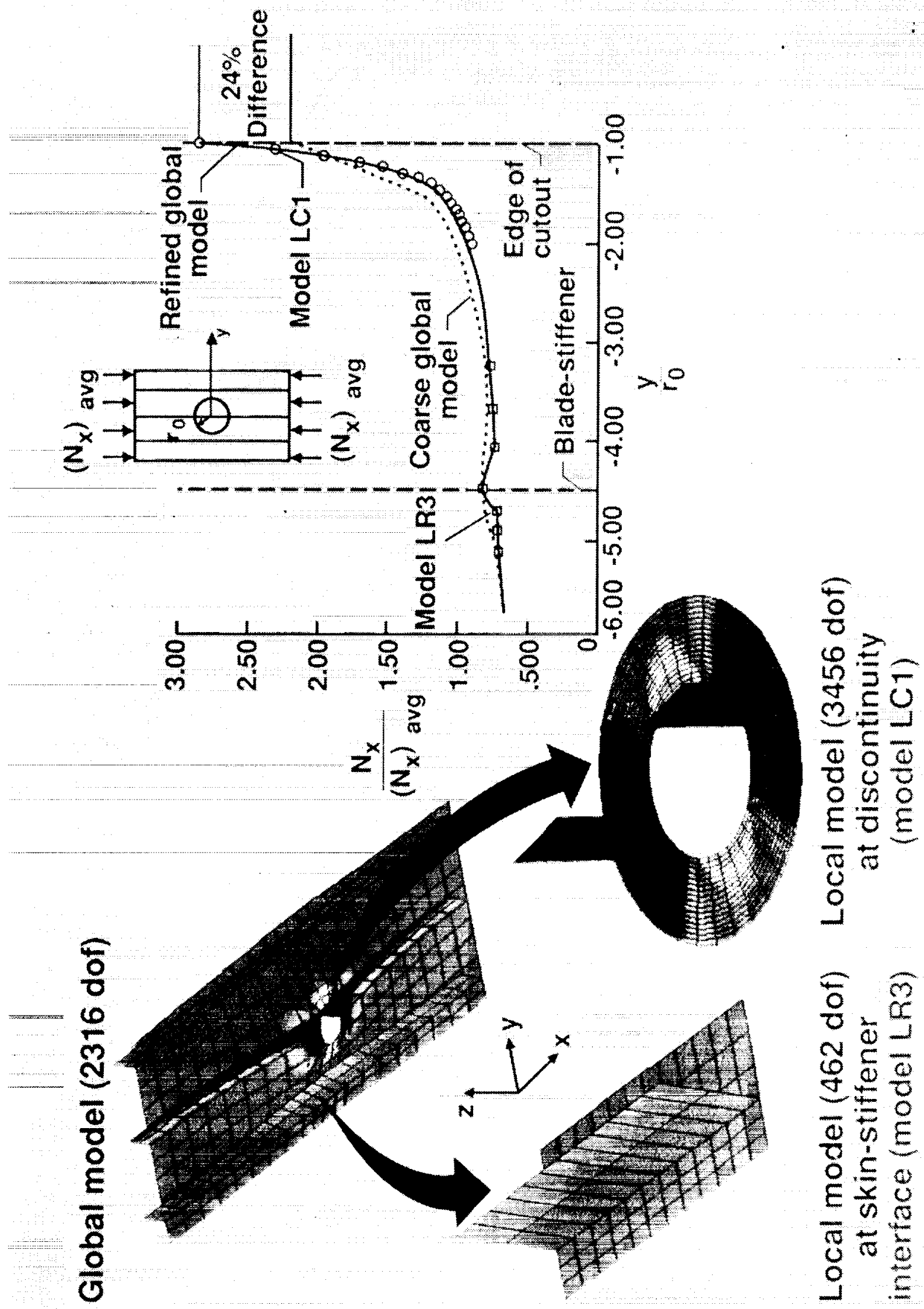

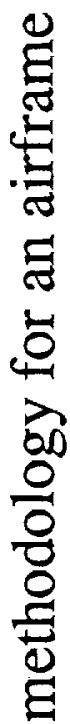

告

䓫

in

宫 


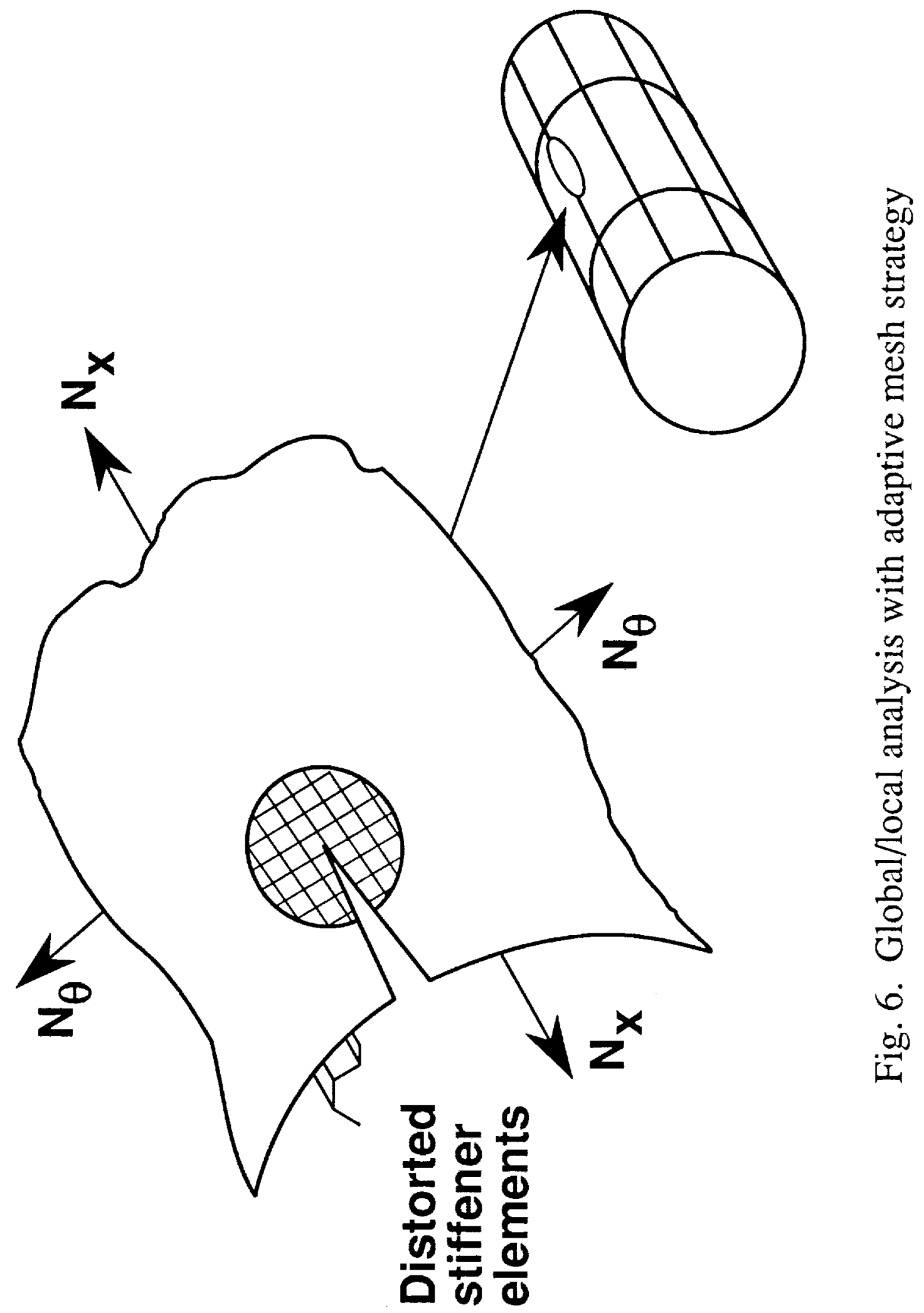




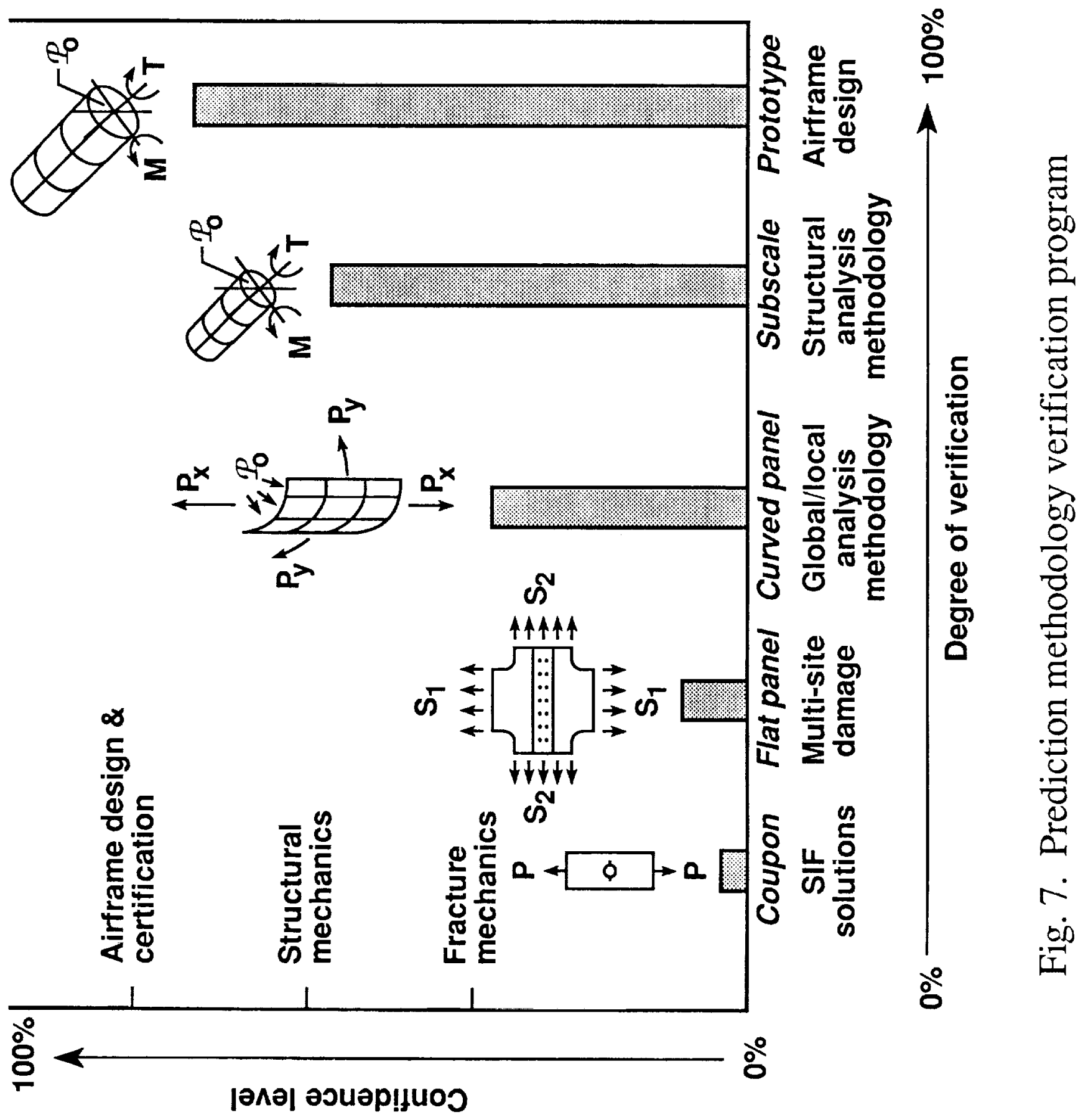



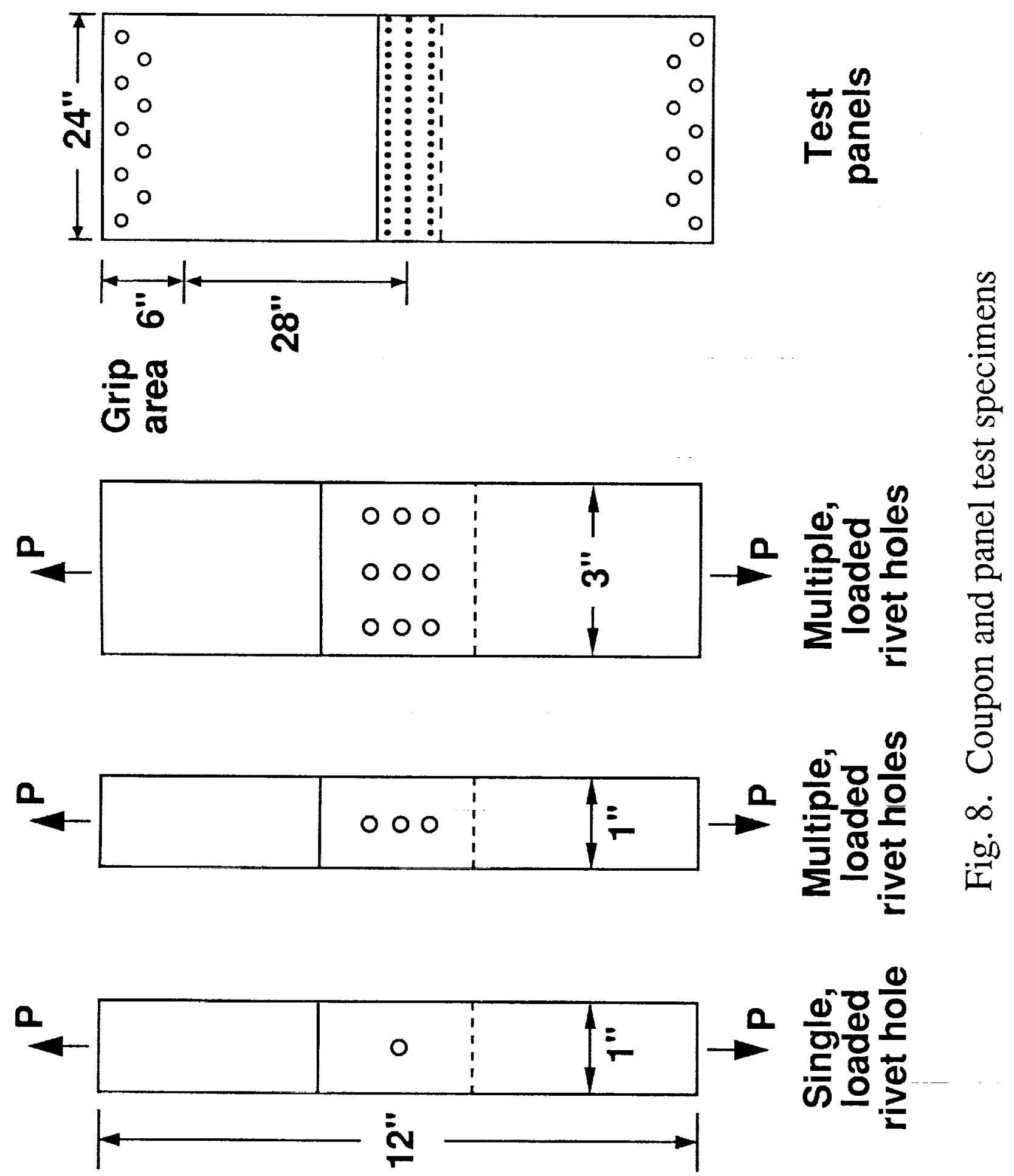
ORIGINAL PAGE IS

OF POOR QUALITY

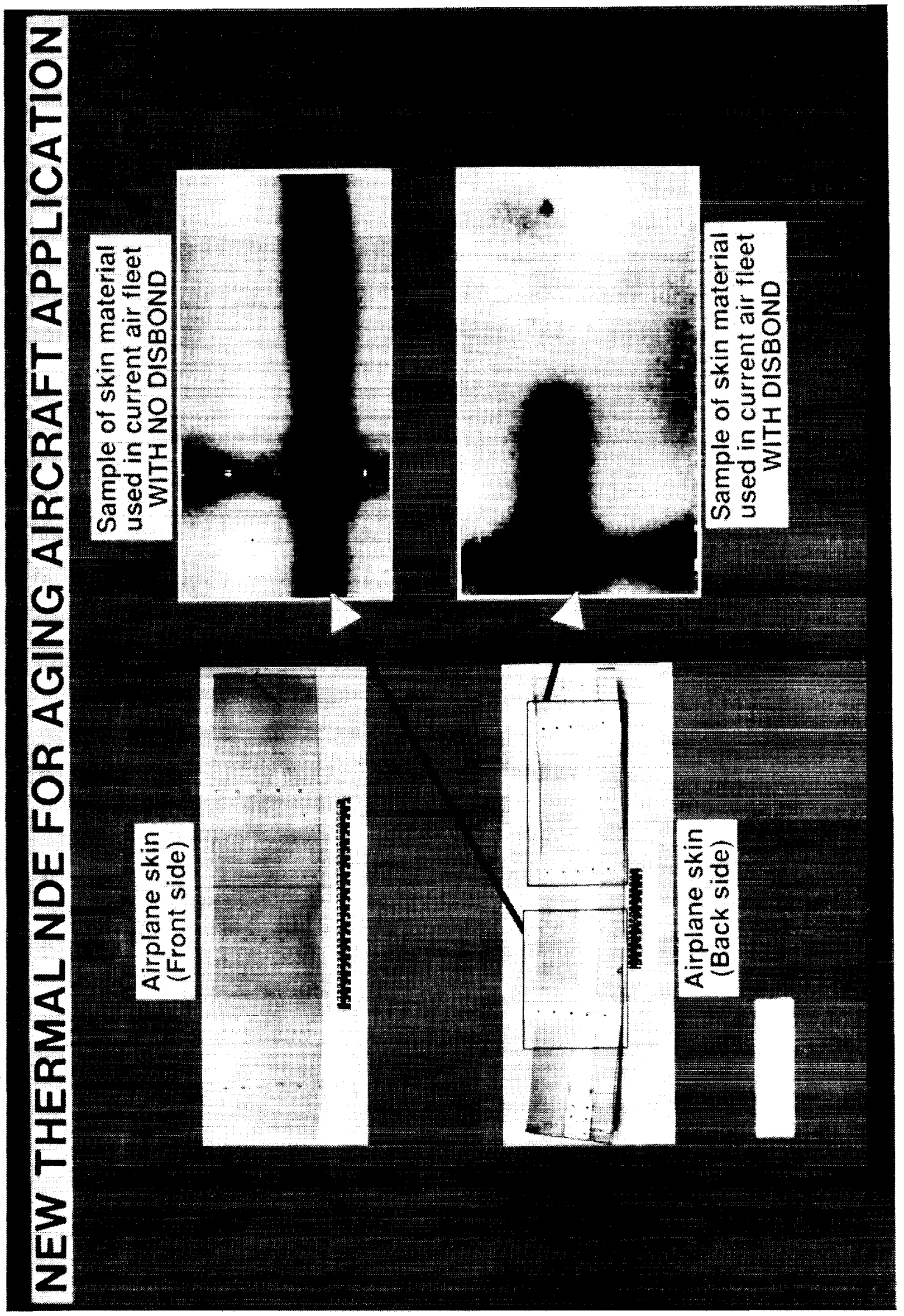

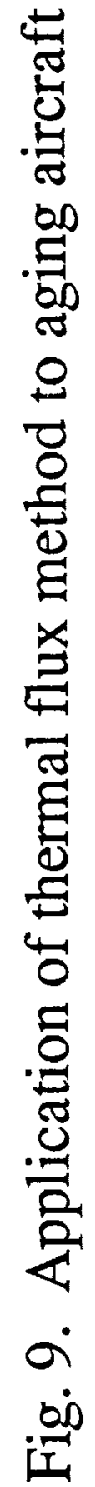




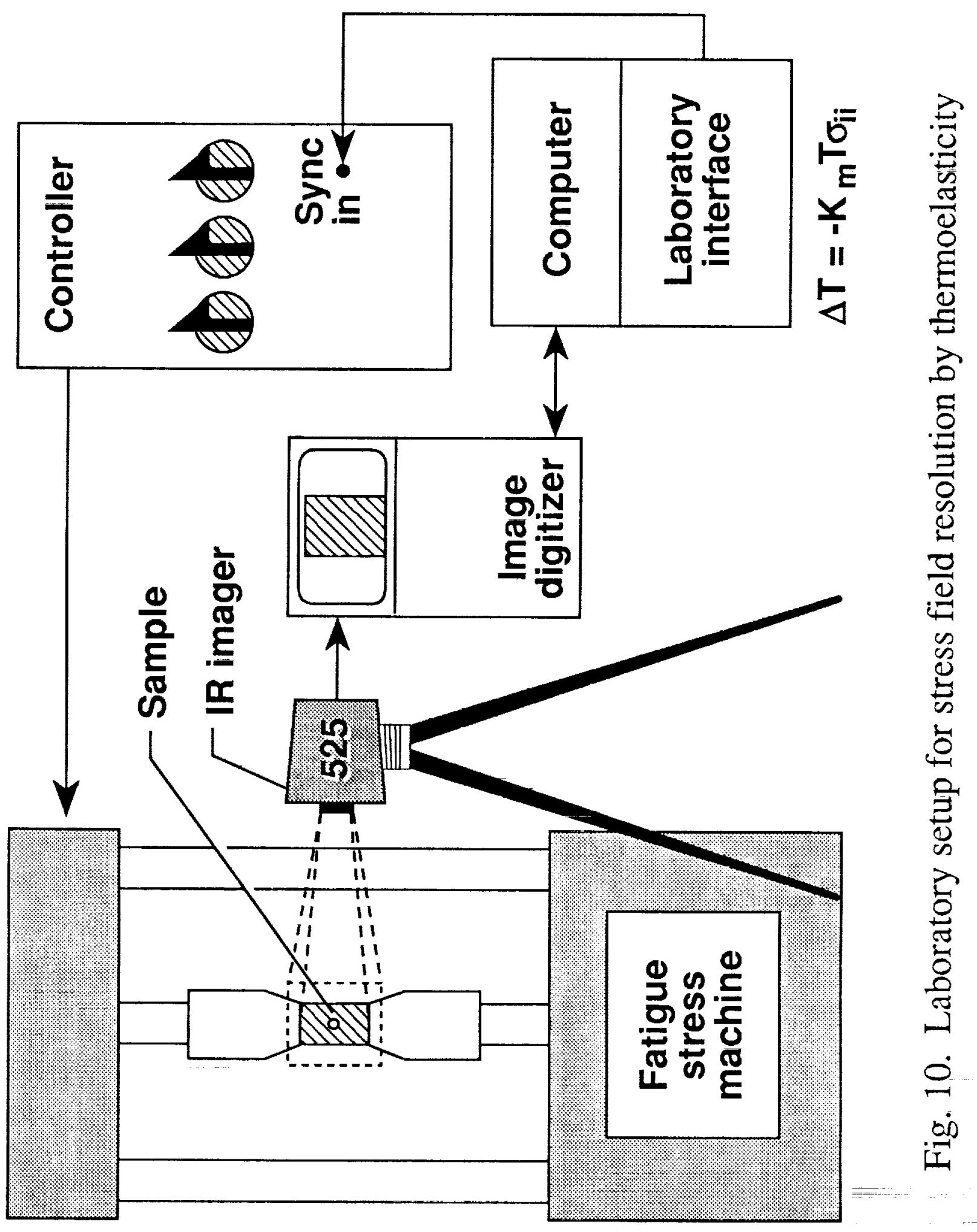




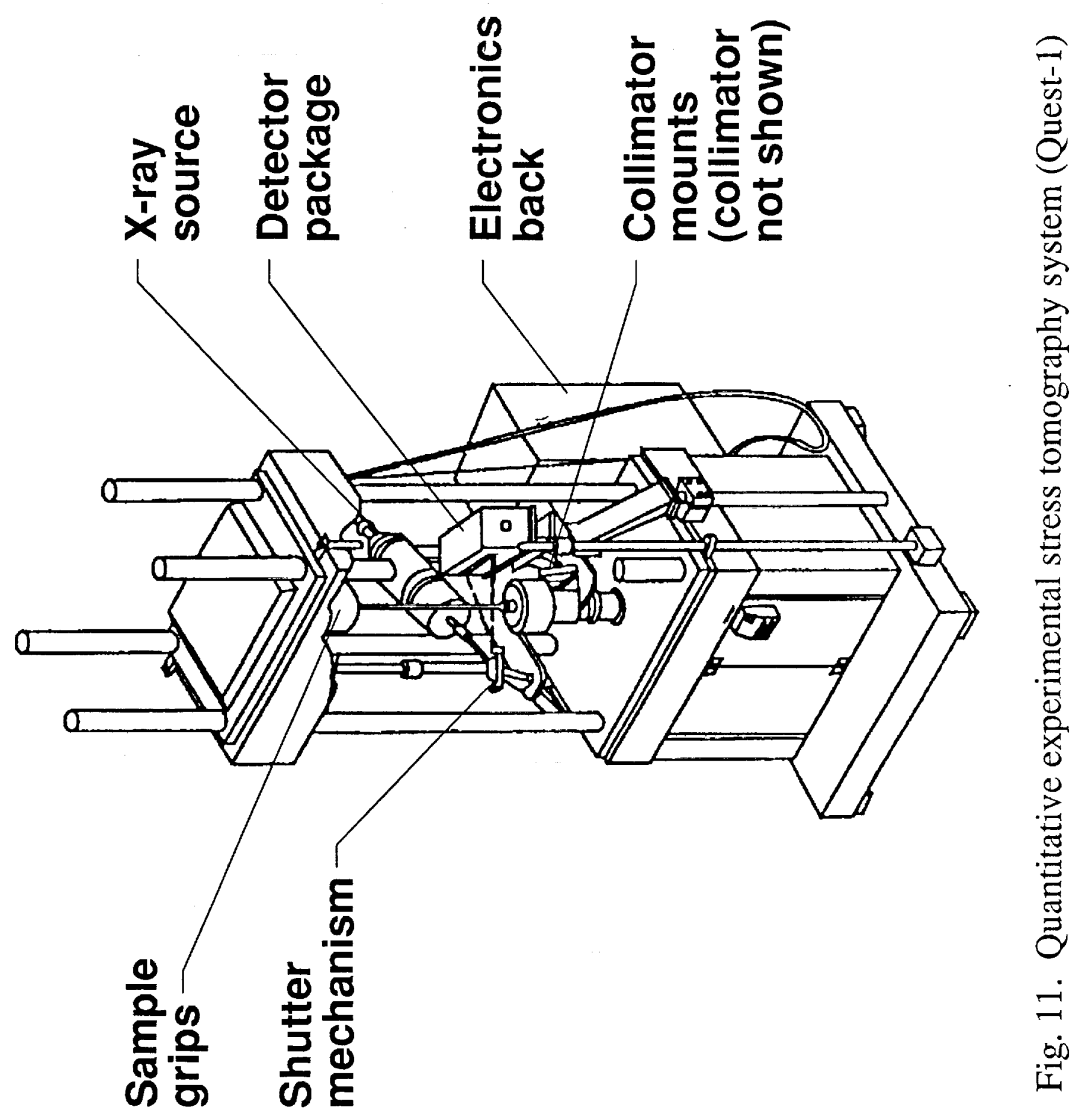




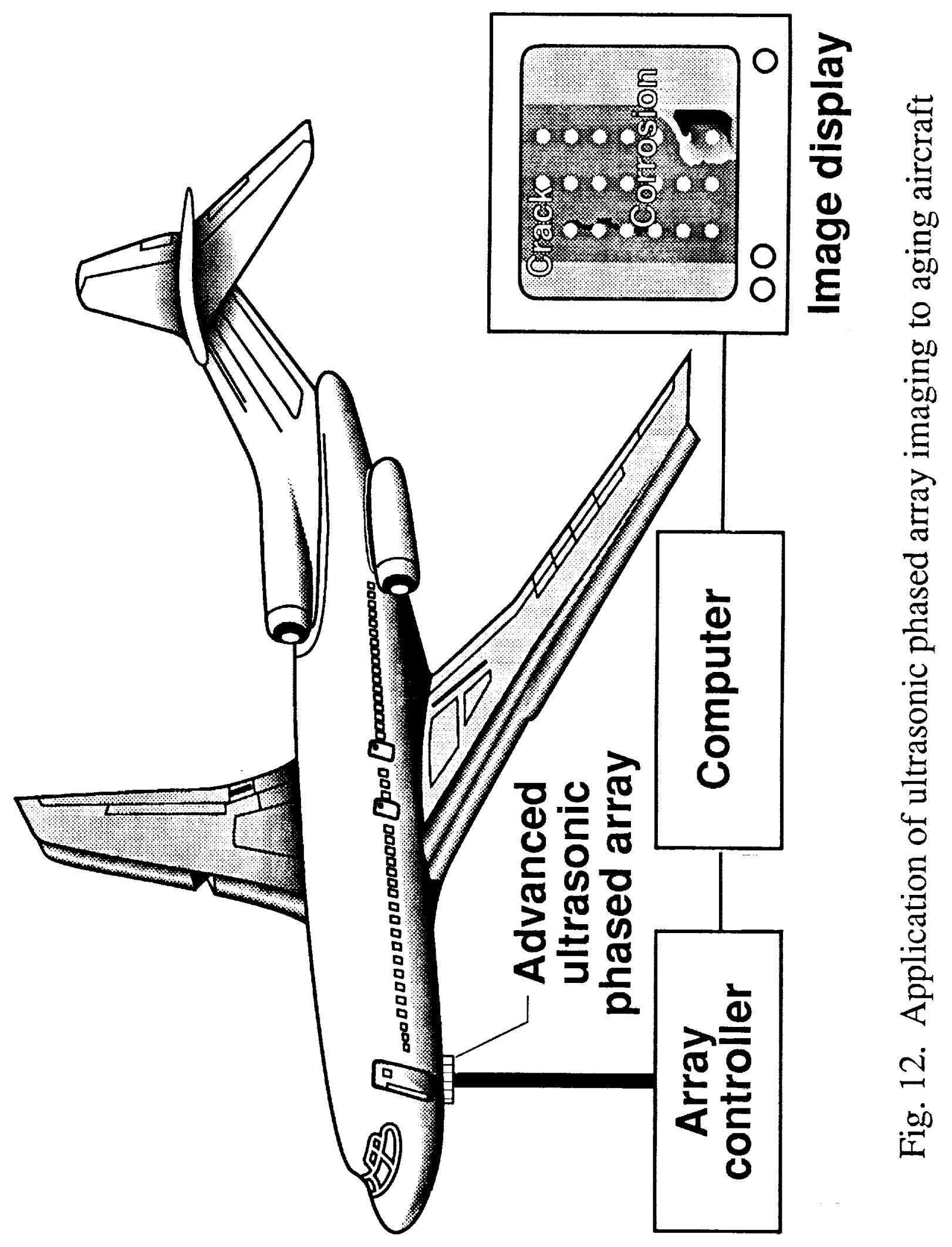




\begin{tabular}{|c|c|c|c|c|}
\hline 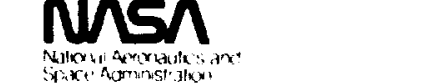 & \multicolumn{4}{|c|}{ Report Documentation Page } \\
\hline $\begin{array}{l}\text { 1. Report No. } \\
\text { NASA TM-102637 }\end{array}$ & \multicolumn{2}{|c|}{ 2. Government Accession No. } & \multicolumn{2}{|c|}{ 3. Recipient's Catalog No. } \\
\hline \multirow{2}{*}{\multicolumn{3}{|c|}{$\begin{array}{l}\text { 4. Title and Subtitle } \\
\text { NASA Airframe Structural Integrity } \\
\text { Program }\end{array}$}} & \multicolumn{2}{|l|}{ 5. Report Date } \\
\hline & & & \multicolumn{2}{|c|}{ 6. Performing Organization Code } \\
\hline \multirow{2}{*}{\multicolumn{3}{|c|}{$\begin{array}{l}\text { 7. Author(s) } \\
\text { Charles E. Harris }\end{array}$}} & \multicolumn{2}{|c|}{ 8. Performing Organization Report No. } \\
\hline & & & \\
\hline \multicolumn{3}{|c|}{ 9. Performing Organization Name and Address } & \multicolumn{2}{|c|}{$505-63-01-05$} \\
\hline \multicolumn{3}{|c|}{$\begin{array}{l}\text { NASA Langley Research Center, } \\
\text { Hampton, VA } 23665-5225\end{array}$} & \multicolumn{2}{|c|}{ 11. Contract or Grant No. } \\
\hline \multirow{2}{*}{\multicolumn{3}{|c|}{ 12. Sponsoring Agency Name and Address }} & \\
\hline \multirow{2}{*}{\multicolumn{3}{|c|}{$\begin{array}{l}\text { 12. Sponsoring Agency Name and Address } \\
\text { National Aeronautics and Space Administration } \\
\text { Washington, DC 20546-0001 }\end{array}$}} & \multicolumn{2}{|c|}{ Technical Memorandum } \\
\hline & & & \multicolumn{2}{|c|}{14 Sponsoring Agency Code } \\
\hline \multicolumn{5}{|l|}{ 15. Supplementary Notes } \\
\hline \multicolumn{5}{|c|}{$\begin{array}{l}\text { 16. Abstract } \\
\text { NASA has initiated a research program with the long-term objective of supporting the aerospace industry } \\
\text { in addressing issues related to the aging commercial transport fleet. The interdisciplinary program } \\
\text { combines advanced fatigue crack growth prediction methodology with innovative nondestructive } \\
\text { examination technology with the focus on multi-site damage (MSD) at riveted connections. A fracture } \\
\text { mechanics evaluation of the concept of pressure proof testing the fuselage to screen for MSD has been } \\
\text { completed. Also, a successful laboaratory demonstration of the ability of the thermal flux method to detect } \\
\text { disbonds at riveted lap splice joints has been conducted. All long-term program elements have been } \\
\text { initiated and the plans for the methodology verification program are being coordinated with the airframe } \\
\text { manufacturers. }\end{array}$} \\
\hline \multicolumn{2}{|c|}{$\begin{array}{l}\text { 17. Key Words (Suggested by Author(s)) } \\
\text { Aging Aircraft } \\
\text { Fracture Mechanics } \\
\text { Multi-site damage } \\
\text { Fatigue crack growth }\end{array}$} & \multicolumn{3}{|c|}{\begin{tabular}{|l} 
18. Distribution Statement \\
$\qquad \begin{aligned} \text { Unclassified - Unlimited } \\
\text { Subject Category - } 39\end{aligned}$
\end{tabular}} \\
\hline $\begin{array}{l}\text { 19. Security Classif. lof this report) } \\
\text { Unclassified }\end{array}$ & $\begin{array}{r}\text { 20. Security Classif } \\
\text { Unclassified }\end{array}$ & his page) & $\begin{array}{l}21 . \text { No. of pages } \\
19\end{array}$ & $\begin{array}{r}\text { 22. Price } \\
\mathrm{A03}\end{array}$ \\
\hline
\end{tabular}


